\title{
AVALIAÇÃO DA INFLUÊNCIA DA VARIABILIDADE DE ÓLEOS NO MICROENCAPSULAMENTO DE FÁRMACOS HIDROFÍLICOS DE BAIXO PESO MOLECULAR POR EMULSIFICAÇÃO A/O
}

\section{EVALUATION OF OIL VARIABILITY AND ITS INFLUENCE ON HYDROPHILIC LOW MOLECULAR WHEIGHT DRUGS MICROENCAPSULATION BY W/O EMULSIFICATION}

\author{
KAMINSKI, G. A. T. ${ }^{1}$; SILVÉRIO, L. C. 1; PASQUALIM, P.1; FIN, M.T. ${ }^{1}$; SASSO, \\ D.G.B. ${ }^{1}$; FUJIWARA, G.M. ${ }^{2}$; RODRIGUES, B.H. ${ }^{3}$; KLOCKER, C.C. ${ }^{4}$;ZANIN, S. M. \\ W. ${ }^{4}$. \\ 1 - Acadêmicos do curso de Farmácia, Iniciação Científica - Universidade Federal do Paraná. \\ 2 - Mestranda do Curso de Pós-Graduação em Ciências Farmacêuticas - UFPR. \\ 3 - FMC Bio Polymer Quimica do Brasil Ltda. \\ 4 - Professora de Farmacotécnica, Curso de Farmácia - UFPR \\ Endereço para correspondência - sandrazanin@ufpr.br
}

REC:11/09 AC: $12 / 09$

\section{RESUMO}

A obtenção de micropartículas por técnicas de emulsificação assumiu grande relevância para o microencapsulamento de fármacos hidrofílicos. O trabalho avalia o uso de diferentes óleos vegetais para o processo de obtenção de micropartículas por emulsificação a/o e observa sua influência no encapsulamento de fármacos de baixo peso molecular.

Palavras-chave: micropartículas, biopolímeros, poloxâmero, alginato, liberação controlada

\begin{abstract}
Microparticles obtainment by emulsification techniques assumed great relevance for hydrophilic drugs microencapsulation. This study aims to evaluate the use of different vegetable oils for microparticles obtainment by w/o emulsification process and its influence in the encapsulation of low molecular weight drugs.
\end{abstract}

Keywords: microencapsulation, bioencapsulation, poloxamer, alginate, controled delivery

\section{INTRODUÇÃO}

As técnicas de obtenção de micropartículas visam a melhoria de várias características de fármacos e formas farmacêuticas, como reduzir freqüência de dose, separar incompatibilidades, melhorar estabilidade de produtos, converter líquidos em sólidos, controlar tamanho de partículas, mascarar gosto e odor, reduzir toxicidade, visando ainda a redução ou eliminação da irritação gástrica, proteção ambiental da umidade, luz, calor e oxidação e a programação e controle da liberação de fármacos em geral tanto de forma sustentada como vetorizada (MAGILL, 1991; SILVA et al., 2003). 
Para a efetiva utilização das técnicas de obtenção de micropartículas deve-se observar o cuidado com revestimentos incompletos, as características de liberação não reproduzíveis e instáveis bem como o elevado custo de produção (VOS et al., 2009). O método ideal de obtenção de micropartículas deve ser simples, reprodutível, rápido e fácil de transpor à escala industrial (GIUNCHEDI e CONTE, 1995).

Existem vários métodos descritos para a obtenção de micropartículas, entre eles estão as técnicas de revestimento, fluidização, nebulização, spray-chilling e spray-desolvation, coacervação, extrusão/solidificação, polimerização e emulsificação/ solidificação.

Através de uma emulsão podem-se preparar microgotas cuja fase interna é solidificada originando as micropartículas (SILVA et al., 2003).

A técnica de emulsificação a/o à frio foi escolhida por apresentar a possibilidade de microencapsular fármacos hidrofílicos termosensíveis e pode ser conduzida utilizando-se polímeros biocompatíveis, como polióis poloxâmeros e alginatos.

Os polióis poloxâmeros são uma série de blocos de copolímeros intimamente relacionados de óxido de etileno (a) e propileno $(b)$ conforme a fórmula geral $\mathrm{HO}\left(\mathrm{C}_{2} \mathrm{H}_{4} \mathrm{O}\right)$ $a\left(\mathrm{C}_{3} \mathrm{H}_{6} \mathrm{O}\right) b\left(\mathrm{C}_{2} \mathrm{H}_{4} \mathrm{O}\right) a \mathrm{H}$. O poloxâmero 407 possui índice de (a) $101 \mathrm{e}($ b) 56 e peso molecular médio de 9.840 - $14.600 \mathrm{com} 71,5$ a $74,9 \%$ de óxido de etileno. Estes copolímeros não iônicos são utilizados como dispersantes, emulsificantes e solubilizantes. O segmento polioxietileno é hidrofílico enquanto o segmento polioxipropileno é hidrofóbico. Possuem uso externo ou interno, considerados não tóxicos, não irritantes e não metabolizados no organismo. Seu EHL é de 18-23 e o pH de uma solução aquosa a 2,5\% p/v é de 6,0-7,4 (ZANIN et al. 2007; ROWE, SHESKEY e WELLER, 2003).

Em solução aquosa a concentração $\geq 20 \%$ e temperatura $\geq 4^{\circ} \mathrm{C}$ transforma-se de uma solução de baixa viscosidade a um gel semisólido (MOEBUS, SIEPMANN e BODMEIER, 2009; SCHMOLKA, 1972).

A gelificação térmica reversa e a baixa toxicidade são propriedades que fazem do poloxâmero um material útil para sistemas de liberação controlada como formador matricial por fomação de gel in situ (JEONG, KIM E BAE, 2002). Esta propriedade permite seu uso em muitos sistemas para liberação controlada e sustentada de fármacos biologicamente ativos como peptídeos e proteínas, urease, insulina e hormônio de crescimento humano (KAMINSKI et al. 2009).

Devido à dissociação das micelas empacotadas do poloxâmero em um excesso de água, a integridade do gel não persiste por períodos prolongados de tempo. A maioria das formulações mostra cinética de liberação sustentada somente por horas, como também, a maioria dos sistemas descritos são líquidos injetáveis à baixa temperatura. Assim, no que se refere à estabilidade em longo prazo os sistemas em pó seco são preferidos (ZANIN, et al., 2007; JEONG, KIM e BAE 2002).

Os alginatos são polissacarídeos de ocorrência natural. O alginato de sódio é derivado do ácido algínico, polímero linear glicuronano consistindo de uma mistura de resíduos dos ácidos $\beta$ - (1口4) - D - manosilurônico e $\alpha$ - (1口4) - L - gulosilurônico arranjados como blocos ao longo da cadeia, onde regiões homopoliméricas estão interdispersas com regiões de estrutura alternantes sem ramificações de fórmula geral $\left(\mathrm{C}_{6} \mathrm{H}_{8} \mathrm{O}\right)_{n}$. Seu peso molecular está tipicamente entre 20.000 a 240.000. O pH é aproximadamente 7,2 para uma solução aquosa a $1 \% \mathrm{p} / \mathrm{v}$. Vagarosamente solúvel na água (ROWE, SHESKEY e WELLER, 2003). 
Eles são capazes de formar géis insolúveis na água por ligação cruzada com cátions divalentes como o $\mathrm{Ca}^{+2}$. Devido ao processo suave de gelificação, um meio aquoso relativamente inerte na matriz e sua a alta biocompatibilidade os sistemas hidrogel contendo alginato também têm sido amplamente usados como formador matricial para microencapsulação de peptídeos bioativos, proteínas e também para células vivas (JAN, 2002; SMIDSROD e SKJAK-BRAEK, 1990). Contudo, os géis de alginato degradam e precipitam em tampão fosfato $0,1 \mathrm{M}$ porque os íons cálcio são removidos pela formação de fosfato de cálcio, conduzindo a rápida liberação do fármaco. Além disso, os géis de alginato mostram uma alta porosidade resultando em altos índices de difusão e, por esta razão, têm sido propostos a formação de complexos estáveis de alginato com policátions tais como poli-L-lisina, quitosana ou polietileneimina. Os géis de alginato de cálcio são assim protegidos contra quelantes de $\mathrm{Ca}^{+2}$ e a porosidade das micropartículas é reduzida, resultando em liberação mais sustentada do fármaco (THU et al., 1996).

A combinação do poloxâmero e de géis de alginato de cálcio em um sistema microparticulado em pó seco mostra-se promissor para superar as restrições dos polímeros individuais. O poloxâmero poderia preencher os poros do gel de alginato e agir como barreira de difusão para os fármacos encapsulados tanto quanto para o meio de dissolução, desta forma reduzindo a troca dos íons cálcio e conseqüentemente, a degradação do gel de alginato-Ca ${ }^{+2}$ (KAMINSKI et al. 2009).

Este estudo objetiva verificar a influência da escolha do óleo utilizado para a obtenção de micropartículas de alginato e poloxâmero por emulsificação a/o. Para tanto foram escolhidos os óleos de amêndoas doce, óleo de oliva e óleo de rosa mosqueta, comumente utilizados em emulsões e com a característica de baixa viscosidade para facilitar a etapa de lavagem do óleo aderido às micropartículas.

A fim de avaliar a formação das micropartículas de forma rápida e prática em bancada por microscopia óptica houve a necessidade da escolha de um corante para diferenciar a fase aquosa da oleosa e facilitar a verificação do encapsulamento do fármaco. $O$ corante lipofílico utilizado inicialmente foi o "fat red". No entanto, o óleo utilizado na técnica serve apenas para a formação das micropartículas por meio de emulsificação a/o, ficando aderido nas micropartículas e sendo posteriormente lavado com isopropanol, impossibilitando assim verificar o encapsulamento do fármaco.

Foi útil para verificar a formação das micropartículas, porém, não o seu conteúdo. Para a vizualização do conteúdo encapsulado procurou-se um corante que tivesse predominância na fase aquosa, tendo em vista que os óleos vegetais são compostos por diversas funções químicas, tais como ésteres, que solubilizam, em parte, substâncias hidrofílicas. Vários corantes foram testados frente a uma mistura de água destilada, óleo de amêndoas doce.

Foi também avaliada a utilização de sais com cores características, os quais se ionizariam permanecendo na fase aquosa. Entre eles foram avaliados o cloreto de cobalto $\left(\mathrm{CoCl}_{2}\right)$ e o sulfato de cobre $\left(\mathrm{CuSO}_{4}\right)$. Embora tenham predominância pela fase aquosa, não forneceram coloração suficiente no primeiro ensaio, sendo testados então com 1,0 g de cada sal, o qual ainda não foi o suficiente e resultou na saturação da solução, reagindo com os polímeros, formando precipitado e impedindo a formação da rede polimérica.

Avaliou-se então corantes hidrofílicos mais intensos, como o alaranjado 2 e o 
azul de metileno. Ambos os corantes foram parcialmente solubilizados pelo óleo vegetal, contudo o azul de metileno (figura 1) mostrou maior afinidade pela fase aquosa do que o alaranjado 2, possivelmente corando o óleo pela sua saturação na fase aquosa.

O corante escolhido para o desenvolvimento do experimento foi então o azul de metileno após avaliação qualitativa. O azul de metileno é um composto aromático heterocíclico, solúvel em água, produzindo solução azul, inodoro, com fórmula molecular $\mathrm{C}_{16} \mathrm{H}_{18} \mathrm{CIN}_{3} \mathrm{~S}$ e massa molar $319.85 \mathrm{~g} / \mathrm{mol}$ (USP, 2009). Além de fornecer a coloração da fase aquosa também foi escolhido como o fármaco a ser encapsulado por representar os fármacos de baixo peso molecular e por ter um método de doseamento farmacopeico simples e preciso.

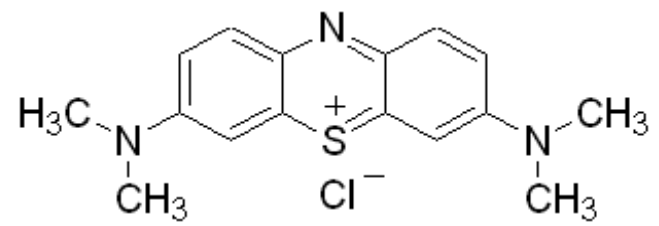

Figura 1. Fórmula estrutural do azul de metileno

\section{MATERIAL E MÉTODOS}

Alginato de sódio (U.S. FMC Biopolymer), Poloxâmero 407 (EMBRAFARMA), Tween 80 (HENRIFARMA), Span 80 (EMFAL), Alaranjado 2 (Merck), Óleo de amêndoas doce (DEG), Óleo de oliva extra-virgem primeira prensa a frio (La Violetera), Óleo de rosa mosqueta (KTB), Azul de metileno (Merck), Cloreto de cálcio (Merck), Fat red (Sigma), Isopropanol (Farmanil quima), Agitador de hélice IKA RW 20, Espectrofotômetro (Shimadzu UV-1800), Seringa (INJEX $5 \mathrm{ml}$ ), Agulha (BD 1,20 x 40 mm) e Microscópio óptico (STUDAR).

Os corantes foram testados frente a uma mistura de $50 \mathrm{~g}$ de água destilada, $50 \mathrm{~g}$ de óleo de amêndoas doce e $0,1 \mathrm{~g}$ de corante. A mistura foi levada ao agitador de hélice por 10 minutos e mantida em repouso para avaliação.

As micropartículas foram preparadas por processo de ligação cruzada externa via emulsão a/o descrito por KAMINSKI et al. (2009). De forma simplificada, a fase aquosa contendo os polímeros, alginato de sódio e poloxâmero 407, e o azul de metileno foi dispersa sobre a fase orgânica (índice de volume de a/o de 1:2) contendo Span 80 como tensoativo e um dos óleos vegetais escolhidos, sob agitação constante. Posteriormente foi acrescentada solução de Tween 80 resultando em um índice de Span 80:Tween 80 de 2:1 sendo a reticulação induzida pelo gotejamento de solução de $\mathrm{CaCl}_{2}$. As micropartículas foram recuperadas através de filtração a vácuo com lavagem por isopropanol suficiente para obter pó branco.

O mesmo método foi utilizado nas mesmas condições para todos os procedimentos, realizados no mesmo dia com os mesmos equipamentos, variando apenas o óleo utilizado. Embora a técnica de preparo de micropartículas por emulsificação produza partículas com poros menores do que outras técnicas, como descrito por Fundueanu et al. (1999), esta técnica ainda produziu micropartículas com poros em torno de $3,5 \mathrm{~nm}$, o que possibilita o trânsito praticamente livre de moléculas de baixo peso molecular.

Em função de sua pequena massa molar de $319,85 \mathrm{~g} / \mathrm{mol}$, o azul de metileno permeou facilmente os poros das micropartículas deixando-as vazias, corando o papel de filtro 
após poucas horas. Devido à essa característica, o doseamento do conteúdo de azul de metileno das micropartículas foi dificultado e foi realizado de forma indireta.

O conteúdo do Kitasato foi recolhido, após ambientalizado com álcool isopropílico e evaporado a temperatura ambiente.

O filtrado foi transferido a um balão de vidro, sonicado, cujo processo acelerou a precipitação do óleo. Refrigerado por 48 horas, resultou na deposição completa do óleo apresentando-se incolor ou esbranquiçado. O sistema foi então transferido para um funil de separação, e a fase alcoólica límpida azulada foi recolhida em um balão volumétrico de $250 \mathrm{ml}$ e preenchido seu volume com isopropanol. O balão foi agitado vigorosamente, sonicado por 5 minutos para posterior doseamento.

Para a obtenção de valores precisos da concentração de azul de metileno não encapsulado foi feita uma curva de calibração com 7 diluições de azul de metileno em álcool isopropílico (figura 2) abrangendo concentrações que variaram de $0,8 \mu \mathrm{g} / \mathrm{ml}$ a $5,6 \mu \mathrm{g} / \mathrm{ml}$ (tabela 1) passando pelo valor de $2 \mu \mathrm{g} / \mathrm{ml}$, indicado no método farmacopeico, descrito na $21^{\text {a }}$ edição da USP para o doseamento espectrométrico de azul de metileno (USP, 1985).

A partir das diluições, a tabela abaixo foi preparada, relacionando as concentrações de azul de metileno e suas respectivas absorbâncias em 563nm e seu gráfico construído.

Tabela 1. Curva de calibração do azul de metileno

\begin{tabular}{ccc}
\hline Diluições & $\begin{array}{c}\text { Concentração } \\
\mu \mathrm{g} / \mathrm{ml}\end{array}$ & Absorbâncias médias \\
\hline 1 & 0,800 & 0,142 \\
2 & 1,600 & 0,302 \\
3 & 2,400 & 0,430 \\
4 & 3,200 & 0,605 \\
5 & 4,000 & 0,736 \\
6 & 4,800 & 0,875 \\
7 & 5,600 & 1,037 \\
\hline
\end{tabular}




\section{Curva de Calibração - Azul de Metileno}

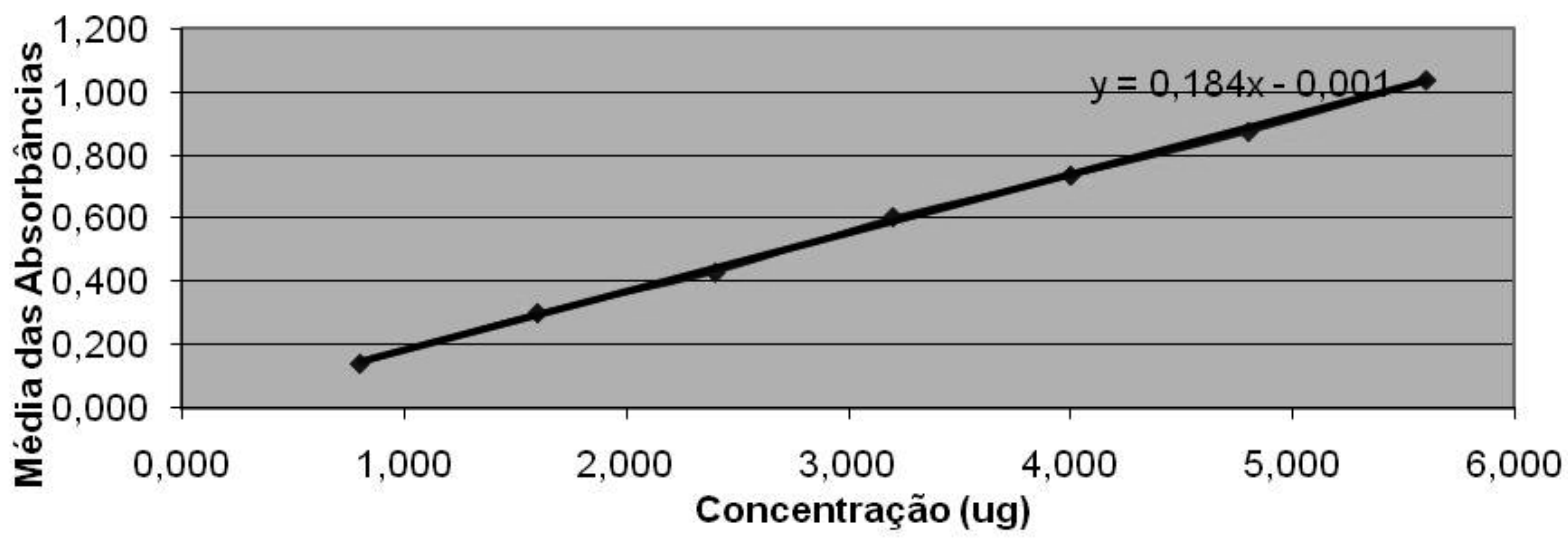

Figura 2 . Curva de calibração do azul de metileno.

\section{RESULTADOS E DISCUSSÃO}

Através das leituras de absorbância dos filtrados foi possível correlacionar com os dados de concentração obtidos na curva de calibração e calcular a concentração de azul de metileno não encapsulado e conseqüentemente avaliar o rendimento do processo, sendo $100 \%$ a massa total de azul de metileno introduzida no processo, apresentado na tabela 2 abaixo.

Tabela 2. Medida indireta das concentrações de azul de metileno nos filtrados.

\section{Concentração} $(\mu \mathrm{g} / \mathrm{ml})$
Tipo do óleo
Absorbância

0,580

Oliva

Amêndoas
0,331

0,538
Rendimento (\%) 


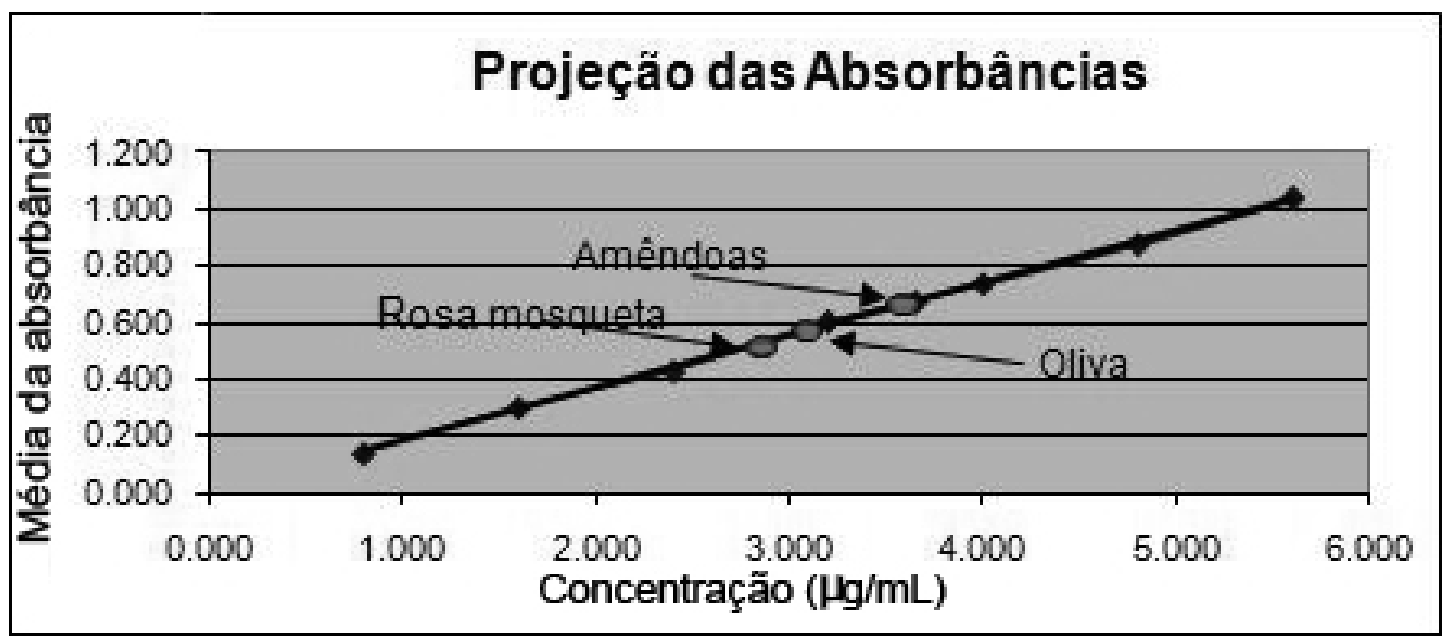

Figura 3. Projeção das absorbâncias dos filtrados.

O rendimento máximo obtido por MOEBUS, SIEPMANN e BODMEIER (2009) com técnica semelhante foi de $15 \%$ com óleo de amendoim para fármacos de alto peso molecular, resultado semelhante ao obtido no procedimento realizado com óleo de rosa mosqueta. No entanto os rendimentos obtidos com o óleo de amêndoas doce e com o óleo de oliva foram diferentes.

A influência do óleo utilizado no processo de obtenção de micropartículas por emulsificação a/o fica evidente, apresentando diferença de rendimento de até 8 vezes. Esta diferença foi maior do que o esperado por serem óleos vegetais de características físico-químicas semelhantes, conforme tabela 3.

Tabela 3. Características físico-químicas dos óleos avaliados

\begin{tabular}{l|cccc}
\hline Características & \multicolumn{3}{|c}{ Tipos de óleo } \\
\cline { 2 - 4 } & Amêndoas doce & Oliva & Rosa mosqueta \\
\hline Densidade & $0,911-0,918$ & $0,910-0,916$ & $0,920-0,930$ \\
Índice de refração & $1,463-1,466$ & $1,467-1,470$ & $1,475-1,476$ \\
Índice de lodo & $95-105$ & $75-94$ & $130-185$ \\
Índice de saponificação & $190-197$ & $184-196$ & $180-190$ \\
Índice de acidez & Máx. 1,5 & Máx. 2 & Máx. 2 \\
Viscosidade a $25^{\circ} \mathrm{C}$ & $67 \mathrm{mPa.s}$ & $81 \mathrm{mPa} . \mathrm{s}$ & $45 \mathrm{mPa} . \mathrm{s}$ \\
\hline
\end{tabular}

As maiores diferenças entre os óleos são o índice de iodo, índice de refração e a viscosidade. O índice de refração é característico para cada tipo de óleo e está relacionado com o grau de insaturação das ligações, compostos de oxidação e tratamento térmico. Este índice aumenta com o número de duplas ligações, conjugações e tamanho da cadeia hidrocarbonada (AMERICAN OIL, 1995). O índice de iodo é uma medida do grau de insaturações dos ácidos graxos presentes em um óleo ou gordura, baseados na reatividade dos carbonos com duplas ligações com halogênios, 
principalmente o iodo, onde ocorre reação de adição, o qual representa o número de gramas de iodo absorvido por 100 gramas de gordura ou óleo (ZAMBIAZI, 2005).

Podemos observar um aumento diretamente proporcional no rendimento com o aumento do índice de iodo. O óleo de rosa mosqueta tendo o maior índice de iodo e o maior índice de refração, possui também o maior número de duplas ligações e conjugações. Isso sugere que o grau de insaturação do óleo tem relação com a formação e/ou estabilização das microgotas na emulsão e sua reticulação por troca iônica, produzindo micropartículas com maior capacidade de microencapsulamento.

Segundo avaliado por SILVA et al. o efeito de diferentes graus de insaturação em emulsões, que visam liberação programada de fármacos, representa a seguinte ordem decrescente de eficácia: Ácido decosahexanóico (DHA) > ácido ecosapentanóico (EPA) > ácidos graxos insaturados $\mathrm{C} 18$ (ácido linoleico) > ácido graxo saturado $\mathrm{C} 18$ (SILVA et al., 2003).

Este estudo mostra uma importante relação entre as insaturações do óleo e as características da emulsão resultante. Ao que indica, quanto maior o número de insaturações de um óleo vegetal, melhor é a qualidade e atividade da emulsão obtida.

Este é o paradoxo das insaturações, pois quanto maior o nível de insaturações, maior a quantidade de dipolos induzidos o que levaria a uma maior polaridade e maior solubilização de azul de metileno na fase oleosa, representando menor rendimento de azul de metileno encapsulado no interior das matrizes de hidrogel. No entanto o maior nível de insaturação parece resultar em uma emulsão de características favoráveis à formação matricial de microgotas de hidrogel contendo fármacos hidrofílicos de baixo peso molecular.

A viscosidade dos óleos também sugere ter um importante papel sobre a formação das micropartículas. Viscosidade é a medida do atrito interno de um fluido. Este atrito torna-se aparente quando uma camada do fluido se move em relação a uma outra camada. A quantidade de força requerida para causar esse movimento é chamada de "cisalhamento". O cisalhamento ocorre quando o fluido é fisicamente movido ou distribuído (FOX, 1992). Aparentemente quanto menor a viscosidade do óleo maior o rendimento de microencapsulamento, possivelmente pelo maior deslocamento das camadas do fluido permitindo uma distribuição mais homogênea das microgotas de hidrogel e uma maior disponibilidade do reticulador gotejado.

Cada método de microencapsulamento apresenta vantagens e desvantagens, portanto, a escolha do método deve começar pelas características do fármaco a ser encapsulado.

No caso da escolha pelo método de microencapsulamento por emulsificação a/o deve-se observar as características do óleo a ser utilizado para a produção de micropartículas por emulsificação, pois exerce grande influência na quantidade de fármaco encapsulada e conseqüentemente no rendimento do processo.

Este trabalho, pelos resultados obtidos, propõe o uso de óleos com alto índice de iodo e/ou índice de refração e de baixa viscosidade. Conclui-se que para este método não é apropriado o uso de fármacos de baixo peso molecular, como o azul de metileno, pois as micropartículas são porosas, o que permite a permeabilidade de moléculas pequenas, sendo indicada para fármacos maiores, como polipeptídios, não se descartando, entretanto a possibilidade de impermeabilização por outros métodos e polímeros como poli-L-lisina, quitosana ou polietileneimina. 
A rápida liberação do azul de metileno por este método pode ser utilizado como um padrão de referência para comparar o tempo de liberação de outros fármacos, pois o aumento do peso molecular dos fármacos tende a aumentar o tempo de retenção dos mesmos.

\section{REFERÊNCIAS}

AMERICAN OIL CHEMISTS' SOCIETY. Official methods and recommended practices of the American Oil Chemists' Society. 4th ed. Champaign, USA, A.O.C.S., [A.O.C.S. Recommended Practice Cd 1 - 25]. 1995.

FOX, R.W., MC DONALD, A.T. Introdução a Mecânica dos Fluidos. $4^{a}$ Edição. Editora LTC, 1992. 662p.

FUNDUEANU, G.; NASTRUZZI, C.; CARPOV, A.; DESBRIERES, J.; RINAUDO, M. Physico-chemical characterization of Ca-alginate microparticles produced with different methods. Biomaterials 20, 1427 - 1435, 1999.

GIUNCHEDI, P.; CONTE, U. Spray-drying as a preparation method of microparticulate drug delivery systems: overview. STP Pharm.a Sci., Paris, v. 5, p. 276-290, 1995.

GOMBOTZ, W. R.; HOFFMANN, A. S.; Immobilization of biomolecules and cells on and within synthetic polimeric hydrogels, in: N.A. Peppas (Ed.), Hydrogels in Medicine and Pharmacy, CRC Press Boca Raton, p. 95 - 126, 1986.

JAN, T. H. H. K.; Alginate in drug delivery systems, Drug Dev. Ind. Pharm. 28, p. $621-630,2002$.

JEONG, B.; KIM, S. W.; BAE, Y. H.; Thermosensitive sol-gel reversible hydrogels, Adv. Drug delivery Rev. 54, p. $37-51,2002$

KAMINSKI, G. A. T.; FIN, M. T.; PAVAN, P.M.; MIGUEL, M. D.; ZANIN, S.M.W. Obtenção, avaliação e recuperação de micropartículas de alginato-poloxâmero utilizando técnica de emulsão a/o. Visão Acadêmica, Vol.10. 2009.

MAGILL, M. Microencapsulamento. Cosmetics \& Toiletries. Vol.3, Mar/Abr 1991.

MOEBUS, K.; SIEPMANN, J.; BODMEIER, R.; Alginate-poloxamer microparticles for controlled drug delivery to mucosal tissue, European Journal of Pharmaceuticals and Biopharmaceuticals 10.1016, 2009.

PEPPAS, N. A.; BURES, P.; LEOBANDUNG, W.; ICHIKAWA, H. Hydrogels in pharmaceutical formulations. Eur. J. Pharm. Biopharm. 50, p. 27 - 46, 2000.

ROWE, R. C.; SHESKEY, P. J.; WELLER, P. J. Handbook of pharmaceuticals excipients. Great Britain: Pharmaceutical Press. 4ed. 2003.

SCHMOLKA, J. R.; Artificial Skin 1. Pluronic F-127 gels for treatment of burns, J. 
Biomed. Master Res 6, p. 571 - 582, 1972.

SILVA, C.; RIBEIRO, A.; FERREIRA, D.; VEIGA, F. Administração oral de peptídios e proteínas: I. Estratégias gerais para aumento da biodisponibilidade oral. Rev. Bras. Cienc. Farm, São Paulo, v. 38, p. 125-140, 2002b.

SILVA, C.; RIBEIRO, A.; FERREIRA, D.; VEIGA, F. Administração oral de peptídios e proteínas: II. Aplicação de métodos de microencapsulação. Rev. Bras. Cienc. Farm, São Paulo, v. 39, n.1, jan./mar., 2003.

SILVA, C.; RIBEIRO, A.; FERREIRA, D.; VEIGA, F. Administração oral de peptídeos e proteínas: III. Aplicação à insulina. Rev. Bras. Cien. Farm., São Paulo, v. 39, n. 1, p. 21-40, 2003.

SMIDSROD, O; SKJAK-BRAEK, G. Alginate as immobilization matrix for cells. Trends Biotechnology n.8. p.71-78, 1990.

THU, B.; BRUHEIM, P.;ESPEVIK, T.; SMIDSROD, P.; SOON-SHIONG, G.; SKJAKBRAEK, G. Alginate polycation microcapsules. II. Some functional properties. Biomaterials, n.17. p.1069-1079, 1996.

United States Pharmacopoeia, 32ª edição, 2009.

United States Pharmacopoeia, 21 a edição, 1985.

VOS, PAUL; BUCKOL, MAREK; GEMEINER, PETER; NAVRÁTIL, MARIÁN. Multiscale requirements for bioencapsulation in medicine and biotechnology. Elsevier Science LTD. Biomaterials 30, 2009.

ZAMBIAZI, R. Tecnologia de óleos e gorduras. Pelotas:UFPel, 2005. 123p.

ZANIN, S. M. W.; MIGUEL, M. D.; BARREIRA, S. M. W.; NAKASHIMA, T.; CURY, C. D.; COSTA,C. K. Enxaguatório bucal: principais ativos e desenvolvimento de fórmula contendo extrato hidroalcoólico de Salvia officinalis. Visão Acadêmica, vol. 8, jan./jun. 2007. 